\title{
NIH Potency Test for Rv-Fc and Rv-K Based Candidate Anti-Rabies Vaccine Produced at Komipharm International Co., Ltd. Korea
}

Abebe M Aga ${ }^{1^{*}}$, Yongkwan Won ${ }^{2}$, Birhanu Hurisa ${ }^{1}$, Ju Hun Kim², Hailu Lemma ${ }^{1}$, Su Jin Lee ${ }^{2}$, Choong-soon Yun ${ }^{2}$, Ho-kyoung Jung ${ }^{2}$, Seong Cheol Moon $^{2}$ and O soo Lee ${ }^{2}$

${ }^{1}$ Ethiopian Public Health Institute, Ethiopia

${ }^{2}$ Komipharm International Co., Ltd. Korea' Department of R\&D center, 17, Gyeongje-ro, Siheung-si, Gyonggi-do, 15094, Republic of Korea

"Corresponding author: Aga AM, Ethiopian Public Health Institute, Addis Ababa, Ethiopia, Tel: +251112134032; E-mail: agagurmu@yahoo.com

Received date: Jun 13, 2016; Accepted date: June 23, 2016; Published date: June 27, 2016

Copyright: (c) 2016 Aga AM, et al. This is an open-access article distributed under the terms of the Creative Commons Attribution License, which permits unrestricted use, distribution, and reproduction in any medium, provided the original author and source are credited.

\begin{abstract}
Potency test for rabies vaccine is required to determine the vaccines potential to induce protective antibody response following vaccination. NIH potency test is the most widely used and internationally recommended potency assay for testing of inactivated rabies vaccines. Komipharm International Co., Ltd. Korea' has produced candidate anti-rabies vaccine from Rv-Fc strain expressing Fc region of Immunoglobulin $\mathrm{G}(\mathrm{IgG})$ originated from canine which enhance virus uptake by immune cells. This vaccine was tested for its potency according to NIH potency test protocol in the presence of Rv-K as a comparison, and $13.49 \mathrm{IU} / \mathrm{ml}$ and $3.16 \mathrm{IU} / \mathrm{ml}$ potency result obtained for Rv-Fc and Rv-K strain respectively. According to OIE recommendation for rabies vaccine, the potency should not be less than $1 \mathrm{IU} / \mathrm{ml}$ to be used for animal vaccination and both vaccines pass the requirement for animal vaccination. The modified rabies vaccine harboring canine Fc $(\mathrm{Rv}-\mathrm{Fc})$ has a high potency and can enhance antibody response after vaccination compared to $\mathrm{PV}$ strain based vaccine. Therefore, these vaccines can be used for animal vaccination at lower cost as it has more than recommended potency value.
\end{abstract}

Keywords: Vaccine strain; Challenge test; Conjugation; Potency test; Rabies; Rv-Fc; Rv-K

\section{Introduction}

Rabies virus causes acute inflammation of the brain and spinal cord in humans and other warm-blooded animals. Approximately 55,000 humans die from the disease worldwide annually [1,2]. Most of the persons at risk live in 90 countries with majority in Asia and Africa, where the rabies reservoir is dog. This figure still underestimates the burden of the disease due to data management and reporting problem in developing country. Consequently, vaccination of dogs considerably reduces the risk to humans and other animals as proved rabies free countries [3].

Significant progress has been made in improving the pre and postexposure treatment of rabies since the discovery of rabies vaccine by Louis Pasteur during 1885 [4]. Following the first vaccination using vaccine prepared from rabbit brain infected with rabies vaccine, several types of anti-rabies vaccines developed for pre and post exposure treatment. These vaccines are live attenuated which is live virus attenuated by several passage on laboratory animal brain, inactivated (killed), DNA-based, conjugate and vector vaccines. Conjugation of the virus with canine Fc can strongly enhance antibody response by facilitating virus uptake by host immune cells, as stated by Takashima et al. [5].

The purpose of evaluating potencies of rabies vaccines has been started during the early Pasteur period and taken as practical standardized test since the time. But many rabies vaccine producers did not practice as routine test on the potency of their products due to different reasons. The test for potency become mandatory before the release of vaccine based on WHO and other regulatory body requirements for biological for humans and animal use [5].

Production of vaccine following good manufacturing practice alone does not assure quality of final product unless the vaccine tested for its consistency of potency requirements. According to OIE recommendation, potency test required for each batch prior to release and designed to correlate with the host animal vaccination-challenge efficacy studies [6]. Batch potency testing of rabies vaccines could be done by challenge, determination of serum antibody response or antigen content of the vaccine correlated with antibody response in immunized mice.

Potency of rabies vaccine assessed in terms of three requirement set by regulatory organization to minimize possible failure of the vaccine quality after marketing. First, the test procedure performed should actually evaluate the property of the vaccine and enough to determine its effectiveness in the prophylaxis of rabies in human or animals. Using a naturally susceptible host like canines, the ideal test correlate and maintain conditions of natural exposure and usual prophylactic treatment to get the maximum test profile [2]. This means the use of case as local street virus introduced through a bite and followed by daily doses of vaccine in the case of those vaccines intended for human use which increase effectiveness of the vaccine. This has, of course, been found to be impractical, as have most types of test where administration of vaccine started after experimental exposure of the test animals. Most tests involve administering multiple doses of vaccine to correlate with multiple doses required for human which followed by viral challenge with fixed virus strain intra-cerebrally. While far from reproducing the situation with natural exposure and the standard schedule of vaccination, such type of test has been shown to reflect closely the ability of the vaccine to protect under natural exposure [7]. Secondly, not all laboratories can obtain large numbers of experimental 
animals easily and they could face problem to repeat experiment test failure occur as laboratory animal costs very high. The time factor is important, thus newly developed vaccine should be held until potency test completed [2]. The third requirement is for standardization of the test reproducibility so that there will be comparable results from one test to another in a single laboratory and between different laboratories [8].

Thus, the NIH potency test uses volumetric method of relative potency calculation compared to standard reference vaccine and compares $50 \%$ end-point dilution of vaccine protecting $50 \%$ of mice in vaccine under test with that of reference vaccine diluted to a final potency of $1 \mathrm{IU} / \mathrm{ml}$. The purpose of this study was to determine potency of inactivated Rv-Fc harboring canine Fc and to compare with $\mathrm{PV}$ strain based $\mathrm{Rv}-\mathrm{K}$ anti-rabies vaccine produced at Komipharm International Co., Ltd. Korea'. This study aimed to identify the effect of canine Fc conjugation on vaccine relative potency in comparison to classical PV strain based vaccine.

\section{Materials and Methods}

\section{Materials}

Reagents: Phosphate buffered saline (PBS) was used for dilution preparation throughout the process of potency comparison.

\section{Biological}

Virus: Challenge virus standard (CVS-11) obtained from CDC Atlanta was used for challenging all immunized mice and control groups. Working dilution of the virus was prepared based on previously determined virus titer.

Vaccines: Experimental vaccine from $\mathrm{Rv}-\mathrm{Fc}$ and $\mathrm{Rv}-\mathrm{K}$ strains produced at Komipharm International Co., Ltd. Korea' and determined for its safety before potency test. Verorab standard rabies vaccine, contains $2.5 \mathrm{IU}$ in one dose $(0.5 \mathrm{ml})$, produced at Sanofi Pasteur was used as reference vaccine according NIH potency test protocol.

Mice: For the immunization and challenge test, Swiss albino mice 10-16 gram weight and 3-4 weeks were used. Mice were quarantined for one week before the day of trial started to adapt to the environment.

\section{Methods}

Viruses used for this study (Rv-Fc and Rv-K) were originated from pasteur virus (PV) strain. Conjugation of the virus was done by

infecting PV virus to canine Fc expressed BHK-21 cells to increase virus uptake by immune cells resulting in high T-helper cell responses. BHK-21 cell lines were purchased from american type culture collection (ATCC). For this purpose, BHK-21 cells expressing canine $\mathrm{Fc}$ and rabies virus were developed by infecting the cells with retrovirus $\mathrm{Fc}$ genes. The infected cells were selected by using antibiotic (G418), and the selections were infected with rabies virus and generate Rv-Fc conjugation. Rv-Fc (RV-Fc generation were confirmed using general immunological method (ELISA, FA and WB) before propagate test vaccines). Vaccine candidate was produced by inoculating PV virus in to canine Fc expressed BHK-21 cell lines and finally 107.0 $\mathrm{TCID}_{50} / \mathrm{ml}$ viruses were obtained after titration. On the other hand, the non conjugated PV virus was harvested from BHK-21 cell lines and 107.0 $\mathrm{TCID}_{50} / \mathrm{ml}$ viruses were obtained. Both inoculates were inactivated with BPL at 1:5000 ratio and followed by safety test to detect virus left over during inactivation and/or to detect contaminant introduced during production process.

Potency test was performed using National Institutes of Health (NIH) test protocol. Mice were assigned to nine different dilutions and one control groups according to the protocol. All mice under reference and test vaccine were immunized twice on day 0 and 7 with $0.5 \mathrm{ml}$ of vaccines on intra-peritoneal route, with different concentrations (1:5, $1: 25,1: 125,1: 625$ and 1:3125) for test vaccine and (1:10, 1:50, 1:250 and 1:1250) for reference vaccine, 16 mice in each dilutions. VeroRab rabies vaccine produced at Sanofi Pasteur was used as reference vaccine after converting to $1 \mathrm{IU} / \mathrm{ml}$. Eight mice were kept separately and used as control during challenge test.

Rabies challenge virus strain (CVS-11) was titrated on Swiss albino mice before the day of challenge test. On day 14th after first immunization, all mice under reference, test vaccine and control groups were challenged with working dilution of $25 \mathrm{MLD}_{50} / 0.03 \mathrm{ml}$ CVS-11 and observed for further 14 days. Deaths during experimental period were recorded as specific and non-specific using fluorescent antibody test (FAT) as confirmatory using brain samples.

\section{Ethics statement}

The project was approved for its ethical consideration in animal handling by the komipharm international Co., Ltd ethics committee for research. All care and treatment were approved by research ethical committee before the research started. Laboratory animals were handled throughout the experiment according to Guide for the Care and Use of Laboratory Animals, Eighth edition.

\section{Experimental work $1(\mathrm{Rv}-\mathrm{Fc})$}

\begin{tabular}{|l|l|l|l|l|l|}
\hline No. & Group name & No. mice & First immunization & Second immunization & Challenge \\
\hline 1 & Test vac. $1: 5$ & 16 & 16 & $09-12-2015$ & $16-12-2015$ \\
\hline 2 & Test vac.1:25 & 16 & $09-12-2015$ & $16-12-2015$ \\
\hline 3 & Test vac. $1: 125$ & 16 & $09-12-2015$ & $16-12-2015$ \\
\hline 4 & Test vac. $1: 625$ & 16 & $09-12-2015$ & $16-12-2015$ & $23-12-2015$ \\
\hline 5 & Test vac. $1: 3125$ & 16 & $09-12-2015$ & $16-12-2015$ \\
\hline 6 & Reference vac. $1: 10$ & 16 & $09-12-2015$ & $16-12-2015$ \\
\hline 7 & Reference vac. $1: 50$ & $2015-12-2015$ & $23-12-2015$ \\
\hline
\end{tabular}


Citation: $\quad$ Aga AM, Won Y, Hurisa B, Kim JH, Lemma H, et al. (2016) NIH Potency Test for Rv-Fc and Rv-K Based Candidate Anti-Rabies Vaccine Produced at Komipharm International Co., Ltd. Korea. J Vaccines Vaccin 7: 326. doi:10.4172/2157-7560.1000326

Page 3 of 5

\begin{tabular}{|l|l|l|l|l|l|}
\hline 8 & Reference vac. 1:250 & 16 & $09-12-2015$ & $16-12-2015$ & $23-12-2015$ \\
\hline 9 & Reference vac. 1:1250 & 16 & $09-12-2015$ & $16-12-2015$ & $23-12-2015$ \\
\hline 10 & CVS virus (working) $10^{\circ}$ & 8 & - & - & $23-12-2015$ \\
\hline
\end{tabular}

Table 1: Groups of mice.

\section{Experimental work $2(\mathrm{Rv}-\mathrm{K})$}

\begin{tabular}{|c|c|c|c|c|c|}
\hline No. & Group name & $\begin{array}{l}\text { No. } \\
\text { mice }\end{array}$ & $\begin{array}{l}\text { First } \\
\text { immunization }\end{array}$ & $\begin{array}{l}\text { Second } \\
\text { immunization }\end{array}$ & Challenge \\
\hline 1 & Test vac. 1:5 & 16 & 06-01-2016 & 13-01-2016 & $\begin{array}{l}19-01-201 \\
6\end{array}$ \\
\hline 2 & Test vac.1:25 & 16 & 06-01-2016 & 13-01-2016 & $\begin{array}{l}19-01-201 \\
6\end{array}$ \\
\hline 3 & Test vac.1:125 & 16 & 06-01-2016 & 13-01-2016 & $\begin{array}{l}19-01-201 \\
6\end{array}$ \\
\hline 4 & Test vac.1:625 & 16 & 06-01-2016 & $13-01-2016$ & $\begin{array}{l}19-01-201 \\
6\end{array}$ \\
\hline 5 & $\begin{array}{l}\text { Test } \quad \text { vac. } \\
1: 3125\end{array}$ & 16 & 06-01-2016 & $13-01-2016$ & $\begin{array}{l}19-01-201 \\
6\end{array}$ \\
\hline 6 & $\begin{array}{l}\text { Reference vac. } \\
1: 10\end{array}$ & 16 & 06-01-2016 & $13-01-2016$ & $\begin{array}{l}19-01-201 \\
6\end{array}$ \\
\hline 7 & $\begin{array}{l}\text { Reference vac. } \\
1: 50\end{array}$ & 16 & 06-01-2016 & 13-01-2016 & $\begin{array}{l}19-01-201 \\
6\end{array}$ \\
\hline 8 & $\begin{array}{l}\text { Reference vac. } \\
1: 250\end{array}$ & 16 & 06-01-2016 & 13-01-2016 & $\begin{array}{l}19-01-201 \\
6\end{array}$ \\
\hline 9 & $\begin{array}{l}\text { Reference vac. } \\
1: 1250\end{array}$ & 16 & 06-01-2016 & 13-01-2016 & $\begin{array}{l}19-01-201 \\
6\end{array}$ \\
\hline 10 & $\begin{array}{l}\text { CVS virus } \\
\text { (working) } 10^{\circ}\end{array}$ & 8 & - & - & $\begin{array}{l}19-01-201 \\
6\end{array}$ \\
\hline
\end{tabular}

Table 2: Groups of mice.

All mice in test and reference group vaccinated with $0.5 \mathrm{ml}$ of each dilution and challenged with $25 \mathrm{MLD}_{50} / 0.03 \mathrm{ml}$ of working dilution of CVS-11. All mice observed for further 14 days following intracerebral inoculation.

\section{Results and Discussion}

\section{Rv-Fc based vaccine}

\begin{tabular}{|l|l|l|l|l|}
\hline No & Dilution & Death & Live & Non-spec. death \\
\hline Gr-1 & $01: 05$ & 1 & 14 & 1 \\
\hline Gr-2 & $01: 25$ & 2 & 14 & \\
\hline Gr-3 & 0.12847 & 3 & 13 & \\
\hline Gr-4 & 0.47569 & 2 & 13 & 1 \\
\hline Gr-5 & 2.21181 & 3 & 13 & \\
\hline Gr-6 & $01: 10$ & 3 & 13 & \\
\hline
\end{tabular}

\begin{tabular}{|l|l|l|l|l|}
\hline Gr-7 & $01: 50$ & 4 & 11 & 1 \\
\hline Gr-8 & 0.21528 & 5 & 9 & 2 \\
\hline Gr-9 & 0.90972 & 7 & 9 & \\
\hline Gr-10 & 100 & 8 & 0 & \\
\hline
\end{tabular}

Table 3: Mice survival rate after challenge.

\section{Calculation of potency}

A volumetric method of calculation is used for calculating potency, which compares the 50\% end-point dilution (vaccine dilution protecting $50 \%$ of mice) of the vaccine under test with that of the International Standard (commercial VeroRab vaccine diluted to a final potency of $1 \mathrm{IU} / \mathrm{ml}$ ). The relative potency (RP) of the vaccine under test was determined by the formula:

$$
R P=\frac{\text { Reciprocal of } E D_{50} \text { of } T V}{\text { Reciprocal of } E D_{50} \text { of } R v} \times \frac{\text { dose of } T V}{\text { dose of } R v}
$$

Where:

$\mathrm{ED}_{50}$-the $50 \%$ effective dose, which is calculated using SpearmanKärber formula

TV-test vaccine

$\mathrm{Rv}$-reference (control) vaccine

Dose-volume of a single vaccine dose

$\mathrm{ED}_{50} \quad$ of $\quad \mathrm{TV} \quad(\mathrm{Rv}-\mathrm{Fc})=\log _{10} 1-\log _{10} 5 / 2+\log _{10} 5 \quad \times$ $(14 / 15+14 / 16+13 / 16+13 / 15+13 / 16)=0-0.35+0.7 \times 4.30=2.66$

ED50 of $\mathrm{Rv}$ (Reference vaccine) $=\log _{10} 1-\log _{10} 5 / 2+\log _{10} 5 \quad \times$ $(13 / 16+11 / 15+9 / 14+9 / 16)$

$$
=0-0.35+0.7 \times 2.69=1.53
$$

It is assumed that a single dose of vaccine under test is $1 \mathrm{ml}$ and 1 $\mathrm{ml}$ of the reference (control) vaccine represents a single dose for humans, then:

$\mathrm{RP}$ (for $\mathrm{Rv}-\mathrm{Fc}$ based vaccine) $=10^{2.66} / 10^{1.53} \times 1 / 1=10^{2.66-1.53} \times$ $1=10^{1.13}=13.49 \mathrm{IU} / \mathrm{ml}$.

\section{Rv-K based vaccine}

\begin{tabular}{|l|l|l|l|l|}
\hline No & Dilution & Death & Live & $\begin{array}{l}\text { Non-spec. } \\
\text { death }\end{array}$ \\
\hline Gr-1 & $01: 05$ & 1 & 14 & 1 \\
\hline
\end{tabular}


Page 4 of 5

\begin{tabular}{|l|l|l|l|l|}
\hline Gr-2 & $01: 25$ & 2 & 14 & \\
\hline Gr-3 & 0.12847 & 5 & 11 & \\
\hline Gr-4 & 0.47569 & 8 & 8 & \\
\hline Gr-5 & 2.21181 & 13 & 3 & \\
\hline Gr-6 & $01: 10$ & 2 & 14 & \\
\hline Gr-7 & $01: 50$ & 4 & 11 & 1 \\
\hline Gr-8 & 0.21528 & 7 & 8 & \\
\hline Gr-9 & 0.90972 & 10 & 6 & \\
\hline Gr-10 & 100 & 7 & 1 & \\
\hline
\end{tabular}

Table 4: Mice survival rate after challenge.

$$
R P=\frac{\text { Reciprocal of } E D_{50} \text { of } T V}{\text { Reciprocal of } E D_{50} \text { of } R v} \times \frac{\text { dose of } T V}{\text { dose of } R v} \text { Where: }
$$

$\mathrm{ED}_{50}$-the $50 \%$ effective dose, which is calculated using SpearmanKärber formula

\section{TV-test vaccine}

Rv-reference (control) vaccine

Dose-volume of a single vaccine dose

$\mathrm{ED}_{50} \quad$ of $\quad \mathrm{TV} \quad(\mathrm{Rv}-\mathrm{K})=\log _{10} 1-\log _{10} 5 / 2+\log _{10} 5$

$(14 / 15+14 / 16+11 / 16+8 / 16+3 / 16)=0-0.35+0.7 \times 3.19=1.88$

$\mathrm{ED}_{50}$ of $\mathrm{Rv}$ (Reference vaccine) $=\log _{10} 1-\log _{10} 5 / 2+\log _{10} 5 \times$ $(14 / 16+11 / 15+8 / 16+6 / 16)$

$=0-0.35+0.7 \times 2.45=1.37$

RP (for $\mathrm{Rv}-\mathrm{K}$ based vaccine $)=10^{1.88} / 10^{1.37} \times 1 / 1=10^{1.88-1.37} \times$ $1=10 .^{50}=3.16 \mathrm{IU} / \mathrm{ml}$.

Based on the result of the two vaccines, there are different in relative potency recorded according NIH potency test calculation. The vaccine under test studied for its potency relative to $1 \mathrm{IU} / \mathrm{ml}$ VeroRab as a reference vaccine using CVS-11 challenge virus standard. The tests follows sequential in its challenge protection for all dilution steps in both reference and test vaccines. Almost all mice under control group were died indicating the effective lethal dose of working challenge virus and the virus titer was strong enough to cause death with $25 \mathrm{MLD}_{50} / 0.03 \mathrm{ml}$. According to NIH protocol, mice dead before five days following challenge were recorded as non-specific death and mice dead without showing specific sign of rabies were confirmed by fluorescent antibody test (FAT). The number of non specific death recorded was removed from the total number during effective dose (ED50) calculation. Most of the non specific deaths were occurred during the day of challenge due to brain inflammation following needle injury which is common to occur with low death rate. According to potency calculation, the vaccines under test showed different potency value which can be indicated by challenge protection in immunized mice relative to reference vaccine with known potency value. The test vaccine $(\mathrm{Rv}-\mathrm{Fc})$ showed the highest potency value $(13.49 \mathrm{IU} / \mathrm{ml})$ and the other vaccine $(\mathrm{Rv}-\mathrm{K})$ showed potency value of $3.16 \mathrm{IU} / \mathrm{ml}$. The result indicate that $\mathrm{Rv}-\mathrm{Fc}$ conjugated vaccine harboring canine Fc molecule is more potent than $\mathrm{Rv}-\mathrm{K}$ strain based vaccine.

\section{Conclusion and Recommendation}

From the result it can be concluded that both vaccines can be used for the effective animal vaccination as it is more than OIE recommendation. These vaccines can be further diluted to get the minimum potency required down to $1 \mathrm{IU} / \mathrm{ml}$ for animal vaccination which helps to deliver at minimum possible lower cost. Specifically, Rv-Fc based vaccine have high potency compared to the PV strain based vaccine. Vaccine can be affected by type of vaccinal strain used, adaptation of the virus to host used for viral propagation, viral concentration before inactivation and modification made to the antigen to increase antigen uptake by immune cells (adjuvant) are the main factors. As potency of a given vaccine can be affected by several factors leading to variation in challenge protection, conjugation of the virus with canine $\mathrm{Fc}$ in this study shows high challenge protection compared to non-conjugated PV strain based vaccine. Thus, in the case of $\mathrm{Rv}-\mathrm{Fc}$ based candidate vaccine, the difference in relative potency was due to the conjugation of the virus with canine Fc which can increase activation of T helper cells, as stated by Takashima et al. [5]. The Rv-Fc based vaccine increase activation of immune cell compared to $\mathrm{PV}$ virus strain resulting in high antibody responses. This conjugation facilitate viral antigen uptake resulting in increased $\mathrm{T}$ helper cell responses. This can result in high relative potency due to high protective antibody in test vaccine compared to reference and non-conjugated PV based vaccines resulting in increased relative potency. This vaccine can be produced at low cost for effective animal vaccination compared to $\mathrm{PV}$ based vaccine. Even though the vaccine under test showed high potency value, it is recommended to evaluate efficacy in target animals to evaluate effective antibody response both In-vivo challenge test and In-vitro virus neutralization before release.

\section{Acknowledgement}

It is our pleasure to thank Mr. Yumyeon Kim for his immense contribution in preparing and availing required input during the whole study period. We would also like to acknowledge Komipharm staffs directly or indirectly contribute to the success of this project. We thank komipharm international Co., Ltd. Korea' for financial sponsorship and assistance during the whole study period.

\section{References}

1. World Health Organization Expert Committee on Biological Standards (1985) Thirty-Fifth Report. World Health Organization Technical Report Series No. 725. WHO, Geneva.

2. World Health Organization Expert Committee on Rabies (1992) Eighth Report. World Health Organization Technical Report Series No. 824, pp: 84.

3. WHO (1994) Requirements for rabies vaccine (inactivated) for human use produced in continuous cell lines (amendment 1992). WHO Expert Committee on Biological Standardization. Forty-third report. Geneva.

4. Yimer E (2001) RABIES IN ETHIOPIA. Sixth SEARG meeting.

5. Tsukamoto YTM, Ota H, Matsumoto Y, Hayashi Y, Otsuka H (2005) Immunization with pseudorabies virus harboring $\mathrm{Fc}$ domain of $\mathrm{IgG}$ makes a contribution to protection of mice from lethal challenge. Vaccine 23: 3775-3782.

6. OIE Terrestrial Manual (2008) Principles of veterinary vaccine production.

7. WHO (1996) Vaccine for humans prepared in human diploid cells. In: laboratory techniques for rabies 280-4.

8. Cliquet F, Aubert M, Sagné L (1998) Development of a fluorescent antibody virus neutralisation test (FAVN test) for the quantitation of rabies-neutralising antibody. J Immunol Methods 212: 79-87. 